\title{
Reorganização concetual e variação linguística no Português Europeu: o caso do verbo meter
}

\author{
José Teixeira \\ ILCH e CEHUM da Universidade do Minho \\ jsteixeira@ilch.uminho.pt
}

\begin{abstract}
Resumo:
Este artigo procurará descrever a forma como, a nível semântico e tomando o caso do verbo meter no Português Europeu, a variação linguística surge a partir da reorganização de uma estrutura concetual. Pretendemos mostrar como a estrutura semântica mais clássica do verbo que implicava a noção de [+interioridade] e Local Contentor se está a reorganizar fazendo desaparecer esta vertente que constituía um dos pilares nucleares do significado. Para a referida demonstração utilizaremos os dados resultantes de inquéritos envolvendo falantes entre os 10 e os 21 anos. Propor-se-á, igualmente, uma análise linguístico-cognitiva que explique a alteração da estrutura interna da semântica de meter.
\end{abstract}

\section{Palabras chave:}

Reorganização concetual, léxico, variação linguística, verbo meter, protótipo.

\begin{abstract}
:
This paper claims to describe the way how, at the semantic level and taking the European Portuguese verb meter case, the linguistic variation arises from the reorganization of conceptual structures. One intends to demonstrate how the verb semantic classic structure that implied the notion of Local Container is being reorganized providing the withdrawal of this feature which was one of the most important features of the verb (meter) main meaning core. For this purpose, one will provide with some data from a large amount of inquiries taken by speakers between the ages of 10 and 21. Finally, one will explain, by using the Cognitivelinguistic approach, the changes in the internal semantic structure of the verb (meter).
\end{abstract}

Key words:

Conceptual reorganization, lexicon, linguistic variation, Portuguese verb meter, prototype.

\section{A janela embaciada da concetualização}

Há duas questões para as quais linguistas e demais investigadores da relação cérebro/cognição se voltam ciclicamente: uma é "como pode o conhecimento do funcionamento do cérebro ajudar-nos a perceber como funciona a linguagem?”. 
A outra é a mesma questão, trocando a ordem dos grupos nominais: "como pode o conhecimento do funcionamento da linguagem ajudar-nos a perceber o funcionamento do cérebro?".

Nos últimos anos do século XX e nos que o século XXI já leva, vários passos foram dados para que estas questões fossem, cada vez mais, o centro de muita investigação das ciências cognitivas. E se é verdade que tudo o que pode ser medido e fotografado, como os experimentos neuronais, vai adquirindo cada vez mais importância neste âmbito científico, não deixa de ser menos verdade que a compreensão da atividade humana que se consubstancia nas línguas naturais é igualmente um utensílio valioso para o mesmo fim.

E então, como é que através dos fenómenos linguísticos, podemos espreitar para dentro do cérebro e da cognição? A este respeito, partilhamos a opinião de que a concetualização e a organização e funcionamento semântico das unidades lexicais são um campo privilegiado para tal finalidade. E se não são uma janela aberta e absolutamente transparente são, pelo menos, uma janela embaciada pela humidade de muita coisa que nos falta limpar para podermos ver com mais acuidade.

Dentro destes pressupostos e partindo do facto de as línguas naturais se construírem e processarem em uso e em inter-relação com os demais mecanismos cognitivos dos seres humanos, a Semântica Cognitiva procura evidências empíricas das relações entre os constructos linguísticos, a organização categorial e as dinâmicas concetuais. Neste sentido, são particularmente interessantes os fenómenos de organização concetual visíveis nas categorias lexicais: como está organizada a respetiva estrutura esquemática, que vertentes metafóricas dela derivam, como é que os falantes fazem saliências e graus de prototipicidade dumas vertentes relativamente a outras, que vertentes se vão impondo e se como consequência de tais fenómenos de variação há reorganização categorial em determinada área lexical.

Pensamos ser particularmente interessante, dentro deste âmbito, o estudo de um fenómeno de variação lexical que se encontra em plena efetivação e que parece constituir-se como uma primeira etapa para um processo de mudança semântica: a (re)organização concetual do verbo meter em Português Europeu (PE).

\section{A mesma palavra com valores diferentes}

A idealização essencialista do significado de uma palavra como algo comum a todos os falantes foi a forma que as análises semânticas do século XX de pendor estruturalista encontraram para resolver a questão de explicar como as línguas 
funcionavam tão bem entre falantes tão numerosos e tão diferentes. Desde Saussure, passando para o estruturalismo europeu e generativismo de Noam Chomsky e outros, era "intuitivo" que o valor de cada unidade lexical deveria ser comum a todos os falantes. Cada palavra deveria ser constituída por um conjunto de feixes semânticos que a definiam intersubjetivamente, sendo esse mesmo conjunto composto por traços considerados simultaneamente suficientes e necessários para a caraterização semântica da unidade.

Porém, as visões menos sistémicas e que validavam o funcionamento pragmático, experiencial e historicamente verificado das línguas foram demonstrando a importância da variabilidade para a variação linguística e o lugar central que estes fenómenos ocupam, quer para o funcionamento sincrónico, quer para a transformação diacrónica.

Dentro desta perspetiva, aparece o modelo da organização concetual em protótipo que começa dentro da antropologia e psicologia ${ }^{1}$ e depois se constituirá como um dos pilares centrais da Semântica Cognitiva.

O protótipo deverá ser entendido como a estrutura concetual modelar que, na língua, corresponde a uma determinada concetualização. Não pode ser concebido, como no início o foi e ainda por vezes assim é referido, como uma "coisa" que representa toda uma categoria. Por exemplo, entender-se que há um determinado fruto concreto que é o modelo através do qual construímos a categoria fruto. Esta coisificação cognitiva não é defensável, porque os efeitos de prototipicidade não se verificam apenas relativamente a realidades físicas como ave ou fruto, mas a todas as organizações mentais linguisticamente traduzíveis. Na realidade, podemos falar não só no(s) uso(s) prototípico(s) do nome árvore, mas igualmente do verbo meter ou do advérbio agora. O protótipo equivale, portanto, a um modelo mental estruturador da categoria, através do qual organizamos mentalmente determinada parte da realidade que sistematizamos num particular item lexical. Esse modelo mental não é rígido, único e uniforme, podendo organizar-se em variantes derivadas e inter-relacionadas ${ }^{2}$.

1 Sobre a noção de protótipo e concetualização, ver, por exemplo, Teixeira 2001, Teixeira 2005 e Silva 2004. A noção de protótipo foi primeiramente utilizada e desenvolvida na Antropologia (Brent Berlin e Paul Kay no estudo da perceção das cores). Dentro da Psicologia, foi sobretudo nos anos setenta do século XX que Eleanor Rosch e a sua equipa de investigação em Psicolinguística utilizaram e desenvolveram o conceito de protótipo no estudo da categorização das cores, das aves e de outras classes linguisticamente traduzíveis em conceitos lexicalizados (Rosch 1973 e 1975, referindo apenas os trabalhos iniciais).

2 Veja-se Teixeira (2001), em que se analisa a estruturação prototípica de frente/trás, mostrando-se como a organização linguístico-cognitiva deste vetor da espacialidade corresponde a vários modelos mentais cognitivamente interligados. 
Ora a organização prototípica das unidades lexicais mostra-nos que os membros que pertencem a uma determinada categoria não valem todos o mesmo relativamente ao centro dessa mesma categoria. Assim, uma categoria é composta por membros centrais e membros periféricos. Os membros centrais possuem as caraterísticas da categoria em mais alto grau e são mais facilmente identificados com ela. Uma maçã ou banana é mais facilmente tida como "fruto" do que as azeitonas ou os limões. Se alguém se movimentar, ainda que com rapidez, apenas com uma perna, tal estado de coisas é mais dificilmente inserível no conceito de correr do que a ação feita por um atleta olímpico dos 100 metros. Ou seja, entende-se que determinados valores/ traços ou vertentes semântico-cognitivas são mais importantes do que outras para a estruturação da categoria e do protótipo (Figura 1).

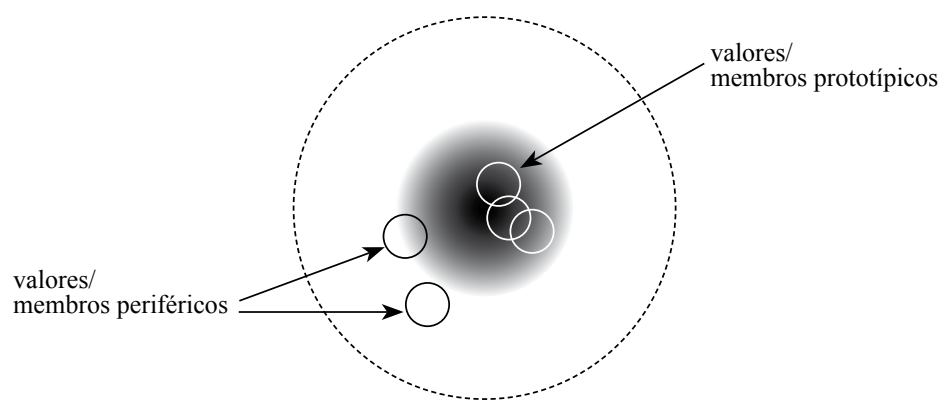

Figura 1

No esquema (Figura 1) a zona central mais escura representa o núcleo do protótipo onde se reúnem os valores tidos como mais importantes para a sua constituição e funcionamento; o diminuir da densidade para a periferia representa a possibilidade da existência de membros periféricos, ou seja, instanciações menos típicas que podem mesmo ser tidas como não pertencentes àquele protótipo (por exemplo pinguim para ave, tomate para fruto).

Esta maneira de encarar a organização semântica das palavras ajuda a compreender o facto de o significado de uma unidade lexical poder variar entre os falantes que a utilizam. Basta que para isso seja diverso aquilo que grupos diferentes entendem que constitui a essência do protótipo.

$\mathrm{O}$ verbo que aqui é analisado insere-se nesta dinâmica. Ele possui, pela tradição normativa que pode ser comprovada pelas descrições lexicográficas, a estrutura prototípica que inclui um CONTENTOR: 
$\mathrm{X}_{\text {Agente }}$ METER $\mathrm{Y}_{\text {Objeto }}$ em $\mathrm{Z}_{\text {Contentor. }}$ :

meter as mãos no bolso;

meter uma faca na gaveta;

meter as mãos na areia (=inserir as mãos dentro da areia);

meter o nariz onde não é chamado.

No entanto, cada vez com maior frequência aparece o uso da valência sem Contentor, em que este é substituído apenas por Lugar:

$\mathrm{X}_{\text {Agente }}$ METER $\mathrm{Y}_{\text {Objeto }}$ em $\mathrm{Z}_{\text {Lugar. }}$ :

meter os sacos no chão (=colocar os sacos no chão);

meter os pratos na mesa;

meter um quadro na parede (=pendurar um quadro na parede).

Considerando, como se procurará demonstrar, que [+interioridade] era valor fundamental do núcleo prototípico de meter, temos aqui um nítido caso de reorganização do referido núcleo, reorganização essa verificável através da variação linguística.

\section{A estrutura semântica de meter e os indícios de alteração}

Como atrás se disse, parte-se do princípio que a estrutura do verbo tem sido estável no Português moderno. Na verdade, consultando os mais representativos dicionários do Português Europeu (e ainda o Caldas Aulete-ver a seguir), exceto no Dicionário da Academia (que procura apresentar os usos mais contemporâneos) não aparece nenhuma exemplificação que não caiba na estrutura $\mathrm{X}_{\text {Agente }} \operatorname{METER} \mathrm{Y}_{\text {Objeto }}$ em $Z_{\text {Contentor }}$

Antes, porém, impõem-se algumas precauções sobre a forma como é possível depreender o significado de uma unidade lexical a partir dos dicionários, para que não aconteça depreendermos que neles estão registadas informações e valores semânticos que realmente não estão.

Teoricamente, uma entrada lexical de um dicionário de sinónimos fornece a descrição e as equivalências mais ou menos aproximadas de um item. No entanto, isto não é bem assim. Frequentemente, o dicionário é construído no pressuposto de que quem o irá consultar é um falante da língua e por isso não é preciso uma explicitação ou descrição do significado completa. Por vezes parece considerar-se que basta uma referência muitas vezes implícita para que o falante "saiba" o que o dicionário "quer 
dizer". Por isso é que aparecem entradas como a seguinte (Dicionário Cândido de Figueiredo):

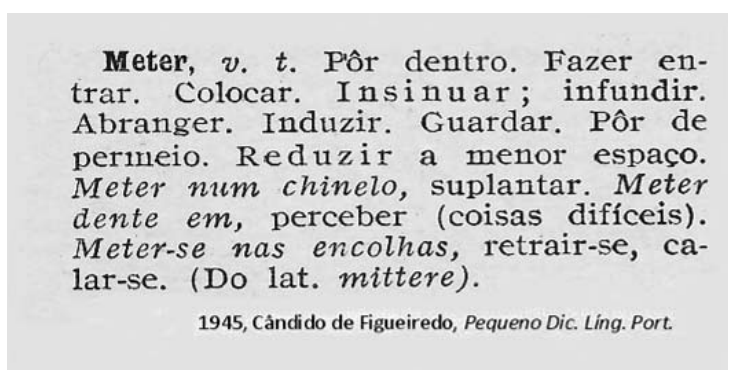

Figura 2: entrada meter no Dic. Cândido de Figueiredo

Este tipo de explicação do significado, que pretensamente apresenta sinónimos, é fundado numa perceção desadequada do que é e de como funciona o significado lexical.

Na realidade, não se pode confundir este, o significado lexical, o significado de uma palavra, com o significado de uma expressão. Nesta não existe, obviamente, apenas o significado de uma palavra, mas o significado resultante da combinatória de várias palavras. Nem sequer se pode confundir o significado da expressão com a soma dos significados das palavras que compõem a dita expressão ${ }^{3}$.

É por causa disto, de se confundir o significado de uma palavra com o significado que resulta das suas combinações, que muitos dicionários apresentam (ver Figura 2) uma lista de hipotéticos sinónimos que não explicam absolutamente nada. "Meter" significa "guardar", como é dito? Se for "meteu o dinheiro no cofre", sim, se for "mete o dinheiro todo na taberna", não; significa precisamente o contrário: gastar tudo, não guardar nada. Ora o que significa "guardar" ou "gastar", não é apenas "meter", mas sim "meter o dinheiro no cofre" ou "meter o dinheiro na taberna". E nem é só "meter no cofre" que significa "guardar". É toda a expressão "meter o dinheiro no cofre". A estrutura "meter X no cofre", não significa apenas "guardar": pode significar "roubar" ("meteu várias vezes a mão no cofre da empresa e foi preso") ou apenas "introduzir a mão" ("meteu a mão no cofre para tirar um documento").

Mas esta metodologia não acontece apenas em obras lexicográficas mais antigas, pode verificar-se nas mais recentes. Por exemplo, no Dicionário da Academia, a

3 Ver Iriarte (2001). 
aceção 13 de meter é "13. Fam. Usar, calçar ou vestir $\approx$ PÔR $\neq$ TIRAR. Meter os sapatos. Meter um chapéu na cabeça. Meter uma camisola. Meter um vestido novo. Meter óculos escuros."

Ora isto não pode ser interpretado (embora os dicionários pareçam empurrar para isso) que a palavra meter significa ou pode ter como sinónimos "usar, calçar ou vestir". Não é "meter" que significa ou equivale a "calçar", mas sim "meter os sapatos" é que equivale a "calçar" e "meter uma camisola" equivale a "vestir".

É por causa destes equívocos que muitos dicionários apresentam listas extensíssimas de aceções como sendo significados de uma palavra quando na realidade são equivalências das combinatórias entre a palavra da entrada e várias outras. A ser assim, cada item pode apresentar uma infinidade de "sinónimos" se o lexicógrafo o fizer combinar com muitas palavras diferentes. Por isso é que, nesta perspetiva, uma palavra pode ter frequentemente como sinónimos duas palavras antónimas, já que ela pode existir em combinatórias antonímicas. Assim se (como diz a aceção 8 do Dicionário da Academia) "meter" significa “esconder ou esconder-se", apresentando como exemplos "Onde é que meteste os óculos? Não sei onde se meteram as crianças", também pode significar o contrário, "mostrar-se", "evidenciar-se": Ele meteu-se à frente do touro". No Grande Dicionário da Língua Portuguesa (José Pedro Machado) é uma das aceções: "Meter-se à cara, aparecer, mostrar-se, procurar dar nas vistas". Ou ainda dizer que meter-se significa "sujar-se" ou o oposto, "limparse" ("meter-se na lama" e "meter-se na banheira").

É por isso uma perspetiva pouco adequada a que faz equivalências entre a entrada dicionarizada e significados ou valores (aceções) que resultam da respetiva combinatória com outros elementos: o significado global não é de uma única palavra, mas do conjunto, de toda a combinatória.

Assim, ao não seguir uma metodologia rigorosa quanto à distinção entre o significado do item e o resultante das respetivas combinatórias, muitas das aceções que vão aparecendo em vários dicionários são bastante arbitrárias, já que dependem das combinatórias que se fazem com a entrada e por isso, como já se viu, cada palavra pode significar tudo, uma coisa e o seu contrário: só para o mesmo item meter, que aqui é ponto de partida, poderíamos ter como "sinónimos" "guardar" e também "roubar", como atrás vimos, "limpar-se" e também "sujar-se", "fugir" e também "lutar" (meter-se nas muralhas e meter-se na luta), "parar" e também "avançar" (meter-se na cama e meter-se a caminho), etc.

É esta visão distorcida sobre o valor/significado de um lexema que permite a aceção 16 do dicionário que mais detalhadamente explana meter, o da Academia: "16. Fam. 
Fazer funcionar um aparelho, um meio ou um produto audiovisual. $\approx$ PÔR. +uma cassete, um disco; +música". Ora o verbo meter pouco tem a ver com o funcionamento do aparelho de música: o verbo indica uma condição necessária mas não suficiente para o aparelho funcionar. Posso meter o disco e não o pôr a tocar. "Meter" não implica funcionamento; posso meter o disco, tentar pôr a tocar e o aparelho não funcionar, por estar avariado. Portanto, "meter o disco" não significa, não equivale a "fazer funcionar um aparelho", como diz o Dicionário da Academia.

\section{A importância dos exemplos para a perceção do significado}

Pelos motivos expostos, para a questão que aqui interessa, a de verificar se os dicionários apresentam usos de meter sem [+interioridade], não é possível tirar conclusões a partir das equivalências dadas pelos dicionários caso elas não sejam acompanhadas de exemplificação. Por exemplo, dar para meter a aceção de "colocar, pôr" não diz nada sobre a existência ou não de interioridade do estado final do objeto: este pode ter sido "colocado/posto" num lugar que implique ou não [+interioridade].

Assim, para detetar usos sem a referida vertente, sem [+interioridade], só o podemos fazer através das exemplificações apresentada nos dicionários a analisar.

O quadro seguinte indica os dicionários de pesquisa e o ano da edição ${ }^{4}$. A indicação do ano serve para se ter uma ideia do período da língua a que correspondem. Notese que o Caldas Aulete, apesar de ter esta sua edição no último quartel do século XX é um dicionário com a primeira edição no século XIX. Indicam-se também o respetivo número de exemplificações que apresentam:

4 AC: Academia das Ciências de Lisboa, 2001, Dicionário da Língua Portuguesa Contemporânea, 2 vols., Verbo, Lisboa.

CA: Dicionário Contemporâneo da Língua Portuguesa Caldas Aulete, 1987 (5ºd.), Rio de Janeiro, Editora Delta (Original: século XIX).

FI: Figueiredo, Cândido, 1945, Pequeno Dicionário da Língua Portuguesa, Bertrand.

GD: Grande Dicionário da Lingua Portuguesa, Porto Editora, 2004.

JP: Machado, José Pedro, 1990, Grande Dicionário da Lingua Portuguesa, Ediclube.

MO: Moreno, Augusto, 1961, Dicionário Complementar da Língua Portuguesa, $7^{\mathrm{a}}$ ed., Editora Educação Nacional, Porto.

PE: Costa, J. Almeida e Melo, 1998, A. Sampaio, Dicionário da Língua Portuguesa, 8 a ed., Porto Editora.

SJ: S/ autor, 1996, Novo Dicionário da Língua Portuguesa, Sistema J, Lello e Irmão Editores.

UN: Universal - Dicionário da Língua Portuguesa, 1995, Texto editores.

VB: Dicionário Verbo - Língua Portuguesa, Verbo, 2006.

VI: Vilela, Mário, 1991, Dicionário do Português Básico, 2ª ed., Asa, Porto. 


\begin{tabular}{c|c|c|c} 
Dicionário & Ano $\left(1^{\mathrm{a}}\right.$ ed $)$ & $\begin{array}{c}\text { Totalidade das } \\
\text { exemplifações }\end{array}$ & $\begin{array}{c}\text { Aceções sem } \\
\text { 'interioridade' }\end{array}$ \\
\hline CA & 1987 (Séc XIX) & 133 & 0 \\
\hline UN & 1995 & 9 & 0 \\
\hline GD & 2004 & 14 & 0 \\
\hline VB & 2006 & 40 & 0 \\
\hline JP & 1990 & 203 & 0 \\
\hline MO & 1961 & 14 & 0 \\
\hline FI & 1945 & 3 & 0 \\
\hline PE & 1998 & 14 & 0 \\
\hline VI & 1991 & 70 & $19+9$ \\
\hline SJ & 1996 & 102 & 0 \\
\hline AC & 2001 & & 0 \\
\hline
\end{tabular}

Salta à vista o facto de, à exceção do último que se reclama do Português "contemporâneo", nenhum dicionário conter uma única exemplificação do uso de meter sem [+interioridade], o que confirma, sem sombra de dúvida, que o valor clássico do verbo implicava o referido traço de [+interioridade]. Serve ainda de confirmação o facto de este traço estar igualmente presente em todas as expressões fixas/ fraseologias abundantemente apresentadas (incluindo as 47 apresentadas no Dicionário da Língua Portuguesa Contemporânea - Dicionário da Academia).

Há, no entanto, casos que à primeira vista podem parecer duvidosos, mas que em nossa opinião não saem da vertente clássica e prototípica.

Assim, no GD (Grande Dicionário da Língua Portuguesa, Porto Editora, 2004) aparece a expressão "meter num chinelo" que poderia ser interpretada como não implicando interioridade, já que se pode supor um chinelo como uma superfície lisa, sem interioridade. No entanto, esta visão não se nos afigura correta, já que um chinelo é sempre perspetivado como algo contentor, "em que se mete o pé". Só é possível supor uma reinterpretação de "meter num chinelo" como "colocar alguém em cima de um chinelo"(?) por causa dos valores últimos ("colocar, pôr em cima") que o verbo está a adquirir.

No VB (Dicionário Verbo - Língua Portuguesa, Verbo, 2006), o grupo 3 de aceções (entre 18) poderia parecer que engloba os valores sem interioridade: "3. t.d. e ind. Colocar ou colocar-se num lugar ou posição, PÔR.” No entanto, os exemplos 
com que estes valores são ilustrados mostram que se pode tratar de vertentes com interioridade: "meter os livros na estante, meter a panela ao lume, meter-se debaixo do chuveiro, meter-se entre a mala e a parede": a estante é um contentor, o lume envolve a panela, e os últimos dois -debaixo do chuveiro e entre a mala e a paredeé a vertente do meter-se "entre" que implica dois pontos englobadores. ("entre o chuveiro e o chão").

José Pedro Machado (JP) apresenta uma interessante Obs. no fim das suas longas 203 aceções de meter: "Obs. Este v. é considerado galicismo quando usado nas aceções de pôr, empregar, fazer contribuir, etc.” Infelizmente não apresenta exemplos, pelo que ficamos sem ter a certeza que se refere a usos de meter sem interioridade. Mas é natural que seja, já que em francês o verbo apresenta esta vertente. Nesse caso, o valor de pôr (sem interioridade) estaria em construções como "meter os pratos em cima da mesa; ", aparecendo a não interioridade evidente.

A ser assim, isto significa que já há algum tempo apareciam frequentes usos de meter sem interioridade, mas que isso era visto não como uma mudança que estava a acontecer na estrutura do verbo em português, mas como influência do verbo francês.

Esta explicação, a da influência francesa, é pouco provável. Caso assim fosse, estas alterações não deveriam acontecer entre as camadas mais populares e juvenis (que não falam assim tanto francês). Ora é inegável que estes novos valores (sem interioridade) se difundem pelo uso popular e numa altura em que o francês já tinha há muito abandonado para o inglês a língua de maior influência nos desvios semânticos (como acontece com género/sexo, tributo/homenagem, realizar/perceber...).

Esta ausência da dicionarização da vertente de meter sem [+interioridade] dificilmente pode ser "coincidência e esquecimento", parecendo óbvio que o verbo possuía classicamente o seu núcleo prototípico estruturado como $\mathrm{X}_{\text {Agente }}$ $M E T E R \mathrm{Y}_{\text {Objeto }} \mathrm{em} \mathrm{Z}_{\text {Contentor. }}$. Aliás, o facto de a alteração só aparecer num dicionário que pretende retratar os usos mais contemporâneos aponta igualmente para a grande probabilidade de a implementação na língua da alteração semântica ser relativamente recente.

\section{A presença ou ausência de [+interioridade] na entrada lexical}

Como se acabou de referir, apenas o Dicionário da Academia, mais voltado para os usos contemporâneos da língua, insere algumas ocorrências do verbo fora da estrutura clássica $\mathrm{X}_{\text {Agente }} M E T E R \mathrm{Y}_{\text {Objeto }}$ em $\mathrm{Z}_{\text {Contentor }}$ 
Podemos sistematizar a distribuição desses usos, no referido Dicionário, em dois quadros-síntese.

Um primeiro que apresenta as aceções que se referem à estrutura clássica e o número de exemplos (com [+interioridade], claro):

\begin{tabular}{|c|c|c|c|c|c|c|c|c|c|c|c|c|c|c|c|c|c|c|}
\hline \multicolumn{19}{|c|}{ Dicionário da Academia: aceções com [+interioridade] de meter } \\
\hline $\mathrm{n}^{0}$ aceção & 1 & 4 & 7 & 8 & 9 & 15 & 19 & 20 & 21 & 22 & 23 & 24 & $25 \mid$ & 26 & $|27|$ & 28 & 29 & 30-fraseologias \\
\hline [+interior. $]$ & 9 & 2 & 3 & 2 & 2 & 2 & 5 & 7 & 0 & 2 & 3 & 2 & 3 & 3 & 0 & 2 & 0 & 47 \\
\hline
\end{tabular}

Um outro, onde se podem ver as aceções sem o traço [+interioridade] ou que admitem possibilidade de dupla interpretação:

\begin{tabular}{|c|c|c|c|}
\hline \multicolumn{4}{|c|}{ Dicionário da Academia: aceções sem [+interioridade] de meter } \\
\hline Aceção & Com interioridade (tradic) & Sem interioridade (novo) & Possibilidade de 2 perspetivas \\
\hline 2 & & $\begin{array}{l}\text { o livro na mesa, o saco no } \\
\text { chão, a mão no ombro }\end{array}$ & \\
\hline 3 & dinheiro no banco & o jantar na mesa & a cafeteira ao lume \\
\hline 5 & & & $\begin{array}{l}\text { o avião mete-nos em qualquer } \\
\text { lado; ele mete-se aí num instante }\end{array}$ \\
\hline 6 & & $\begin{array}{l}\text { o livro de pernas para o ar, o } \\
\text { vestido do avesso }\end{array}$ & \\
\hline 10 & muito dinheiro no projeto & & $\begin{array}{l}\text { energia no trabalho, calor na } \\
\text { discussão }\end{array}$ \\
\hline 11 & no rol das compras; na lista & & meter em primeiro lugar \\
\hline 12 & & $\begin{array}{l}\text { papel nas paredes, manteiga } \\
\text { nas torradas }\end{array}$ & \\
\hline 13 & & $\begin{array}{l}\text { os sapatos, um chapéu na } \\
\text { cabeça, uma camisola, um } \\
\text { vestido novo, óculos escuros }\end{array}$ & \\
\hline 14 & & & açúcar no café, sal na comida \\
\hline 16 & uma cassete, um disco & & + música \\
\hline 17 & & & aquecimento central \\
\hline 18 & & & $\begin{array}{l}\text { um nome a uma pessoa, culpas a } \\
\text { alguém, uma alcunha }\end{array}$ \\
\hline 19 & em sarilhos; em problemas & $\begin{array}{l}\text { os papéis em ordem; em } \\
\text { risco; o carro a trabalhar }\end{array}$ & \\
\hline
\end{tabular}


Como se pode comprovar através desta distribuição, há já, neste dicionário, a perceção da diferença da estrutura verbal das duas vertentes. A prova é que a nova estrutura sem [+interioridade] é apresentada logo como aceção 2 (entre 30). No entanto, esta aceção é apenas uma das que apresenta o novo valor do verbo, novo valor esse que aparece distribuído em outras aceções ao longo da entrada. Aliás, nesta aceção 2 , a vertente sem interioridade que é apresentada é apenas uma subespecificação da estrutura nova $\mathrm{X}_{\text {Agente }} M E T E R \mathrm{Y}_{\text {Objeto }}$ em $\mathrm{Z}_{\text {Lugar }}$ em que meter implica apenas "pôr em cima": "2. Pop. Colocar em cima, depositar sobre. $\approx$ PÔR. $\neq$ RETIRAR, TIRAR. Meter o livro na mesa. Meter o saco das compras no chão. Meteu-lhe a mão no ombro." Faltam, portanto, as aceções de meter sem interioridade e que não implicam "em cima", como "meter um quadro na parede", "meter a música mais alto/mais baixo" "meter os sapatos".

Por outro lado e comprovando a falta de perceção da importância da distinção que aqui tratamos na organização da entrada lexical, no grupo das aceções apresentadas logo a seguir $\left(n^{\circ} 3\right)$ aparecem misturadas exemplificações que ilustram a ausência da vertente de interioridade ("meter o jantar na mesa"), outras em que o vetor está, como canonicamente, presente ("meter dinheiro no banco") e ainda outros casos que permitem uma dupla interpretação ("meter a cafeteira ao lume").

\section{Os dados obtidos}

Para se poder constatar até que ponto a alteração do núcleo prototípico de meter aparece como real variante para os falantes mais jovens da zona Braga-Porto, elaborou-se um inquérito constituído por 10 frases contendo o verbo e que foi aplicado em escolas dos distritos de Braga e Porto ${ }^{5}$. Pedia-se aos inquiridos que assinalassem um dos três graus de aceitabilidade para cada frase, como se pode ver no inquérito:

Idade $\operatorname{Sexo}(\mathrm{M} / \mathrm{F})$ Local

Diz se nas seguintes frases o verbo meter faz muito, pouco ou nenhum sentido, ou seja, se está a ser bem usado, usado de uma forma esquisita ou mal usado. Põe uma cruz no rectângulo que reflecte a tua opinião:

5 O inquérito foi aplicado pelos seguintes alunos do $1^{\circ}$ ano do Mestrado em Português Língua Não Materna em fins de 2010 e princípios de 2011: Ermelinda Silva, Paula Freitas, Maria do Céu Pereira, Liliana Alves, Maria Júlia Ferreira, Isabel Maria Pereira, Sofia Kiseleva, Alice Ribeiro, Eugénia Gomes, Iuliia Serebriakova, Isabel Madureira e Laura Rodrigues. 


\begin{tabular}{l|l|l|l}
$1-$ Ela meteu a faca na gaveta. & $\begin{array}{c}\text { Bem usado, faz } \\
\text { sentido }\end{array}$ & $\begin{array}{c}\text { Esquisito, faz } \\
\text { pouco sentido }\end{array}$ & $\begin{array}{c}\text { Mal usado, não } \\
\text { faz sentido }\end{array}$ \\
\hline $2-$ Ela meteu a gaveta na faca. & & & \\
\hline $3-$ Ela mete muito amarelo no desenho. & & & \\
\hline $4-$ Mete os pratos na mesa. & & & \\
\hline $5-$ Ela meteu os sapatos nos pés. & & & \\
\hline $6-$ Por causa do frio, vou meter um casaco & & & \\
mais grosso. & & & \\
\hline $7-$ Vou meter a carteira na moeda. & & & \\
\hline $8-$ Mete a música mais alto! & & & \\
\hline $9-$ Para ler, preciso de meter os óculos. & & & \\
\hline $10-$ Ele meteu as mãos em cima da cabeça! & & & \\
\hline
\end{tabular}

Obtiveram-se cerca de 1200 respostas para cada frase ${ }^{6}$.

\begin{tabular}{l|r|r|r|c}
\multicolumn{7}{c}{ Total em Portugal (Braga e Porto) 10-21 anos } & \\
\hline Frases & Bem & Esquis & Mal & TOTAIS \\
\hline 1-Ela meteu a faca na gaveta. & 980 & 179 & 47 & 1206 \\
\hline 2-Ela meteu a gaveta na faca. & 24 & 93 & 1078 & 1195 \\
\hline 3-Ela mete muito amarelo no desenho. & 295 & 714 & 176 & 1185 \\
\hline 4- Mete os pratos na mesa. & 767 & 349 & 91 & 1207 \\
\hline 5-Ela meteu os sapatos nos pés. & 261 & 607 & 329 & 1197 \\
\hline 6-Por causa do frio, vou meter um casaco mais grosso. & 441 & 502 & 252 & 1195 \\
\hline 7-Vou meter a carteira na moeda. & 26 & 104 & 1064 & 1194 \\
\hline 8- Mete a música mais alto! & 837 & 292 & 64 & 1193 \\
\hline 9- Para ler, preciso de meter os óculos. & 593 & 476 & 127 & 1196 \\
\hline 10-Ele meteu as mãos em cima da cabeça! & 736 & 373 & 80 & 1189 \\
\hline
\end{tabular}

6 Os totais das respostas não coincidem absolutamente em todas as frases como, idealmente deveria acontecer. Haverá uma diferença entre $0,5 \%$ e $1 \%$ entre a totalidade das respostas (máximo 1207) às 10 frases. Isto deve-se ao facto de, por exemplo, alguns inquiridos terem hesitado nalgumas frases e não assinalarem nenhuma opção. As frases que obtêm menos respostas são a última e a $\mathrm{n}^{\circ} 3$. Na última frase, talvez porque sendo a última alguns inquiridos demoraram mais tempo e não conseguiram preencher todo o inquérito. A frase 3 foi a que obteve menos respostas: é onde é maior a percentagem de "Esquisito": terá levado um grande número a hesitar e não colocar nada? Alguns disseram que os irmãos mais novos, na escola primária, usavam esta forma de dizer e que eles, mais "velhos" os corrigiam porque achavam que estava mal. Estas pequenas discrepâncias não alteram em nada a globalidade dos resultados, já que a pequeníssima parte de respostas em falta não modificariam a globalidade dos mesmos resultados. 
Como se pode verificar, havia 3 frases de controlo da validade das respostas. Uma correspondente ao uso prototípico do verbo (1-Ela meteu a faca na gaveta.) e duas de interpretação impossível relativamente ao saber habitual sobre o conhecimento do mundo (2- Ela meteu a gaveta na faca.; 7- Vou meter a carteira na moeda.). Em todas, os resultados comprovam a validade das respostas, na medida em que quase a totalidade considerou bem usado o verbo em 1. e mal usado em 2. e 7.. Notar, no entanto, como na frase prototípica com o uso clássico do verbo (1.) o número de hesitações é maior do que nas frases "más" 2. e 7. o que parece comprovar a tendência de esbatimento do protótipo clássico de meter com interioridade.

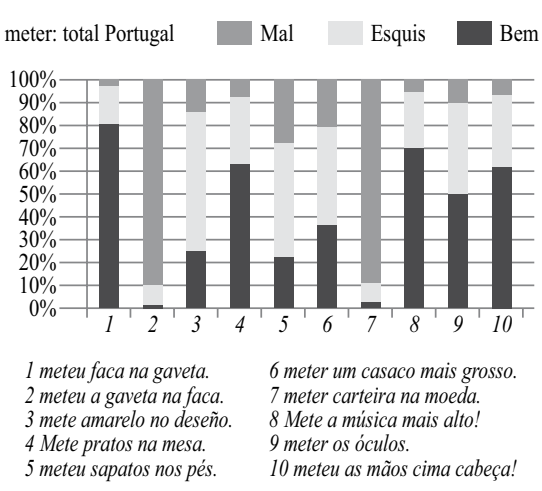

Figura 3

Se dividirmos os resultados em dois grupos etários (dos 10 aos 15 anos e outro dos 15 aos 21 anos -ver Figuras 4 e 5), verificamos que os resultados são esmagadoramente coincidentes entre si e coincidentes com os resultados globais. Parece-nos, por isso, que a partir da sua observação se podem inferir algumas conclusões e tendências.
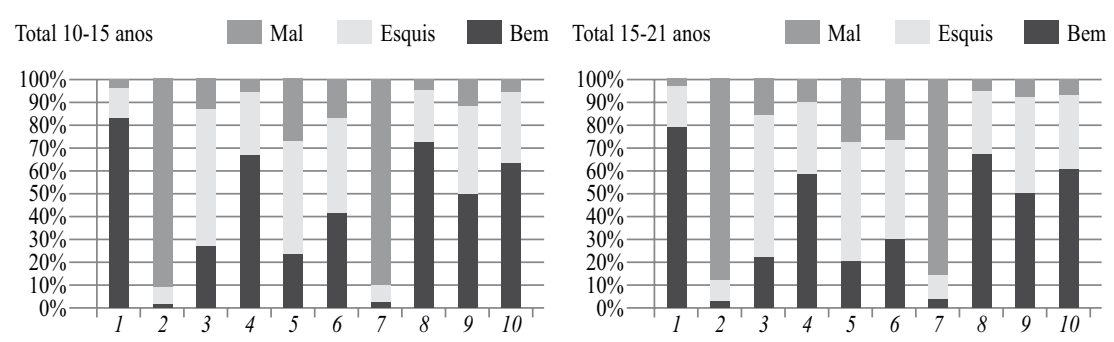

1 meteu faca na gaveta. 2 meteu a gaveta na faca. 3 mete amarelo no deseño. 4 Mete pratos na mesa. 5 meteu sapatos nos pés.

6 meter um casaco mais grosso. 7 meter carteira na moeda. 8 Mete a música mais alto! 9 meter os óculos. 10 meteu as mãos cima cabeça!

Figuras 4 e 5

A primeira é que não há dúvida sobre a aceitabilidade de meter sem o vetor de [+interioridade], passando a estrutura do verbo de $\mathrm{X}_{\text {Agente }} M E T E R \mathrm{Y}_{\text {Objeto }}$ em $\mathrm{Z}_{\text {Contentor. }}$ para $\mathrm{X}_{\text {Agente }} M E T E R \mathrm{Y}_{\text {Objeto }}$ em $\mathrm{Z}_{\text {Lugar. }}$ Todas as frases que utilizam o verbo sem 
[+interioridade] são globalmente validadas, sendo reduzido o número de falantes que considera o verbo mal usado ${ }^{7}$.

Podemos verificar que há um grupo de usos de meter em que a aceitação é maior: meter a música mais alto, meter os pratos na mesa e meter as mãos em cima da cabeça. Há ainda meter os óculos que baixa a aceitabilidade (fica-se pelos 50\%), ficando, no entanto, esta bem acima da rejeição (apenas cerca de 10\%).

Estas diferenças parecem, assim, permitir concluir que a aceitabilidade das construções é diretamente proporcional à frequência do respetivo, à familiaridade do falante com cada combinação sintagmática. Se bem que seja muito difícil ter estatísticas sobre isso, é nossa intuição que para estes falantes as combinatórias que eles aceitam e não estranham tanto são as que para eles são as que mais frequentemente utilizam com o verbo meter.
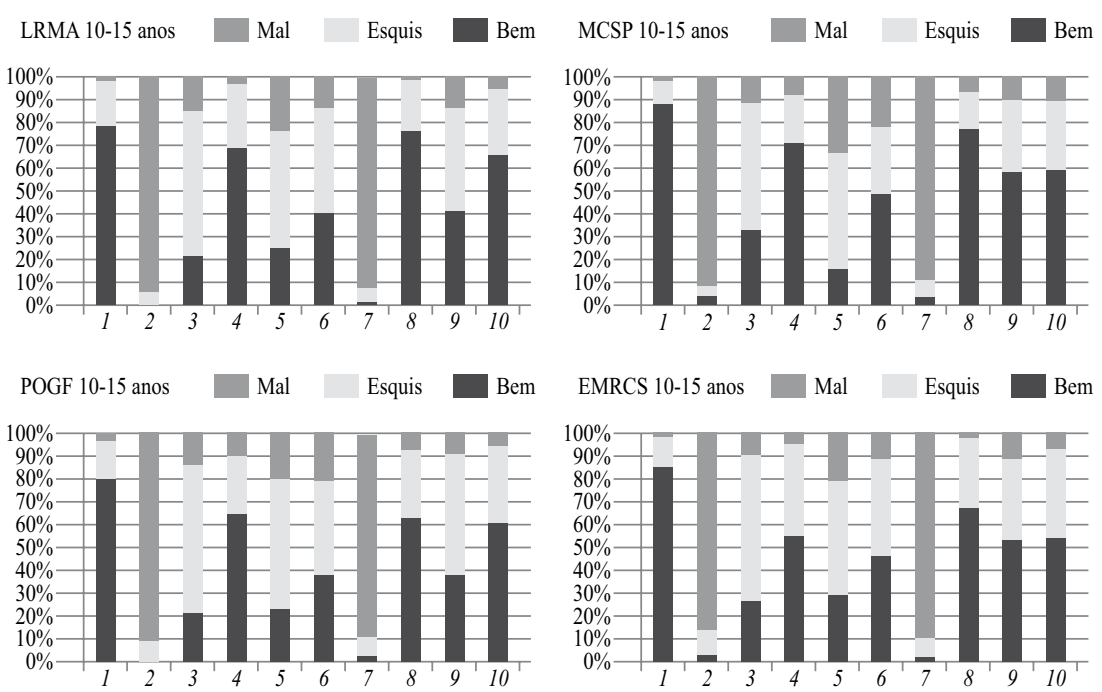

1 meteu faca na gaveta. 2 meteu a gaveta na faca. 3 mete amarelo no deseño. 4 Mete pratos na mesa. 5 meteu sapatos nos pés. 6 meter um casaco mais grosso. 7 meter carteira na moeda. 8 Mete a música mais alto! 9 meter os óculos. 10 meteu as mãos cima cabeça!

Figura 6: quatro maiores inquéritos dos 10-15 anos

7 Pode verificar-se nos Anexos como os resultados obtidos junto a filhos de emigrantes a viverem na Suíça (Genebra e Zurique) coincidem com os obtidos em Portugal. Aparentemente esperar-se-iam resultados diferentes, mais “conservadores". A proximidade dos resultados é provavelmente explicável pela forma como hoje a televisão e as comunicações globais (internete e tudo o que possibilita) espalham as tendências na variação linguística. 
Comprove-se analisando a Figura 6 onde se contrapõem os quatro maiores inquéritos na faixa etária 10-15 anos. Não pode ser coincidência que em todos meter a música mais alto e meter os pratos na mesa sejam as duas combinatórias dominantes entre as relativas à nova aceção sem [+interioridade]. E não pode ser coincidência que o mesmo se verifique comparando o inquérito global 10-15 anos com o de 15-21 anos (Figuras 4 e 5). Reforça ainda esta inferência (que a aceitabilidade da combinatória é diretamente proporcional à frequência de uso) reparar-se como entre estes dois usos também há uma constante: meter a música mais alto é ligeiramente mais aceitável do que meter os pratos na mesa em todos os inquéritos, exceto num em que a aceitabilidade é praticamente idêntica.

Outro dado interessante que se pode constatar a partir dos resultados é o de que o processo de reorganização do protótipo é um processo no verdadeiro sentido do termo, implicando não apenas uma temporalização para a reorganização, mas também que não há o abandono abrupto da organização prototípica clássica. Na verdade, poderse-ia esperar que a nova estrutura argumental $\mathrm{X}_{\text {Agente }} M E T E R \mathrm{Y}_{\text {Objeto }}$ em $\mathrm{Z}_{\text {Lugar }}\left(\right.$ meter $\left.^{2}\right)$ vem substituir a anterior $\mathrm{X}_{\text {Agente }} M E T E R \mathrm{Y}_{\text {Objeto }} \mathrm{em} \mathrm{Z}_{\text {Contentor }}\left(\right.$ meter $\left.^{l}\right)$ num determinado grupo de falantes, de tal modo que desaparece a necessidade de uma zona semântica incluidora de [+interioridade] e os dois usos (com/sem interioridade) passam a constituir duas valências nucleares e em pé de igualdade do novo conceito rearranjado. Poderíamos supor, assim, a existência de uma variação não inclusiva, na medida em que a língua apresentaria duas estruturas autónomas: o falante ou escolhia uma ou escolhia outra, sem as integrar numa estrutura inclusiva (Figura 7).

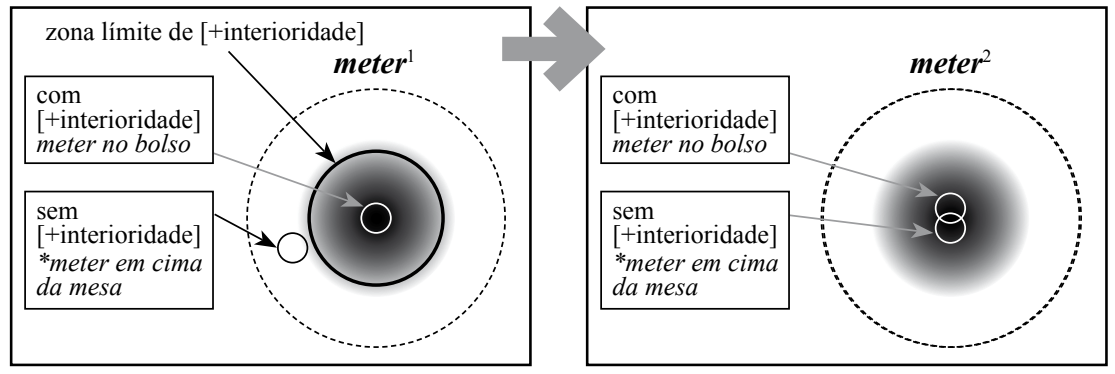

Figura 7: representação da hipótese da variação não inclusiva

Ora não é isto que se passa, como facilmente os resultados comprovam. Os falantes, mesmo tendo como aceitável meter $^{2}$, continuam a considerar como prototípico meter $^{l}$. Todos os resultados de todos os inquéritos, globais e parciais são inequívocos: para os mesmos falantes, as duas frases com meter $^{l}$ obtêm praticamente a totalidade da aceitabilidade enquanto as de meter $^{2}$ variam da forma que se pode comprovar. 
E pensando bem, teria que ser mesmo assim: na língua não há substituições bruscas, mas verdadeiras alternativas entre variantes. Ora para que uma variante o possa ser, o falante tem que saber que variantes tem à disposição, ou seja, isto implica que ele conheça as relações entre a organização concetual primeira e a que agora aparece com nova organização. Só quando o processo de substituição está completo, só quando se verificou totalmente o processo de mudança é que não é obrigatória a perceção da variação inclusiva.

Assim, o esquema que melhor representa o funcionamento do processo, não é o da substituição (Figura 7) mas um que evidencie a coexistência do protótipo mais antigo com a nova valência que dentro do conceito se está a projetar como geradora do rearranjo concetual (Figura 8).

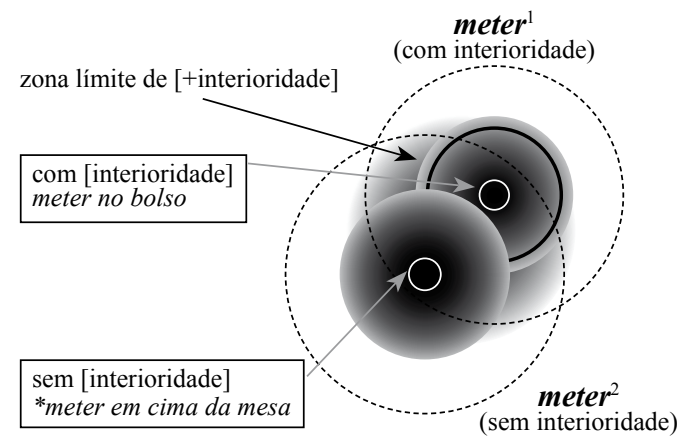

Figura 8: representação da hipótese da variação inclusiva

Enquanto funcionarem como variantes, não há, entre as duas estruturas (meter ${ }^{l} e$ $m e t e r^{2}$ ), alteridade mas inclusão, sabendo o falante qual é a original (mais primitiva) e qual a que está em processo de aceitabilidade. Ou seja, durante o processo, o falante tem alguma consciência da diacronia, ao contrário do que tão veementemente é negado no Curso saussureano:

Para o sujeito falante a sucessão no tempo é inexistente: ele está perante um estado. Por isso, o linguista que quiser compreender este estado deve fazer tábua rasa de tudo o que o produziu e ignorar a diacronia. Só suprimindo o passado se pode entrar na consciência dos sujeitos falantes. (Saussure 1978:145).

Como consequência e ao contrário do que diz Saussure (ou pelo menos lhe é atribuído) o linguista que quiser "compreender a consciência dos sujeitos falantes" não pode mesmo ignorar a diacronia, já que para o sujeito falante esta lhe aparece 
concretizada nos usos verificados da geração mais velha, podendo ele, sujeito da novidade, perceber o processo de variação e intuir, ainda que não reflexivamente, a mudança possível.

A grande zona de hesitação (consubstanciada nestes inquéritos na opção "Esquisito, faz pouco sentido") e que é tanto maior quanto mais novos e menos frequentes são os usos de meter sem [+interioridade] prova precisamente a perceção de novidade do novo valor nos próprios falantes que o utilizam. Aliás, alguns dos inquiridos disseram que os irmãos mais novos, na escola primária, usavam estas formas de dizer (as menos frequentes) e que eles, mais "velhos" os corrigiam porque achavam que estava mal. E como última prova desta consciência da diacronia, repare-se que comparando os dados globais dos dois grupos etários diferentes, onde apesar de tudo há apenas uma diferença média de 5 anos (Figura 4 e 5), em todos os usos de meter $^{2}$ a aceitabilidade é sempre ligeiramente menor do que em meter $^{l}$. Dificilmente esta regularidade pode ser entendida como coincidência, mas antes como prova de que, por um lado o novo uso entra através das gerações mais novas e talvez de que o aumento da interação linguística com os mais velhos (com o protótipo "clássico") é um elemento retardador da transformação da variação em mudança efetivada. Ou seja, os do grupo 15-21 anos já possuem uma maior interação linguística com os falantes do padrão clássico e portanto já são mais conscientes da diferença de valor relativamente às duas estruturas diferentes $\left(\right.$ meter $^{l}$ e meter $\left.{ }^{2}\right)$. E, em nosso entender, deve ser esse confronto que pode retardar a transformação da variação em mudança.

\section{As configurações percetivas potenciadoras da variação}

Temos estado a contrapor as duas estruturas de meter em variação como estruturas que se diferenciam pela inclusão ou não de [Lugar Contentor] no estado de coisas do verbo, concretamente em relação ao Lugar ocupado pelo objeto no final desse mesmo estado de coisas. E tem-se apresentado essa diferença como correspondendo a duas estruturas discretas: presença ou ausência do traço [+interioridade], traço esse implicado, naturalmente, pelo contentor.

Mas se os valores prototípicos são valores nucleares de uma estrutura semântica, como podem eles ser obliterados e abandonados pelos falantes? Se são centrais, se ocupam o coração da estrutura semântica e, neste caso, do estado de coisas do verbo, como é possível que sejam neutralizados pelos falantes?

Quando se trata dos chamados valores periféricos, secundários, conotativos (como por vezes se diz) é facilmente compreensível que a estrutura semântico-concetual 
os possa ir perdendo ou reforçando e isso contribua para a alteração periférica de determinados valores do item lexical. Mas quando tal acontece naquilo que pode ser tido como a essência prototípica da rede semântico-concetual a explicação não pode ser a mesma. Ou então, afinal não há nada de prototípico, nuclear, e todos os traços semânticos deverão ser considerados como de igual importância e valor, mais ou menos nos moldes das perspetivas componenciais das teorias das condições necessárias e suficientes.

Como defendemos a estruturação hierárquica do núcleo de uma categoria, parecenos que a explicação do surgimento de alterações nos núcleos prototípicos terá de ser explicada pelos casos em que esses mesmos usos prototípicos possibilitam configurações concetuais alternativas. Ou seja, quando a vaguidade (que a construção de um conceito sempre tem) potencia mais do que uma perspetiva de enfoque.

Quanto a nós, é precisamente isto que se vai passando com a estrutura prototípica de meter. É que esta estrutura é potenciadora de variação na construção concetual relativamente a [Contentor], como todas as construções do género. Por exemplo, uma mão pode ser vista como um contentor (quando em concha ou fechada) ou como uma superfície (quando aberta). Veja-se, a propósito desta dualidade, em inglês a variação entre "in the street" e "on the street", explicada como a diferença de perspetiva em conceber a rua como um contentor (ruas estreitas com casas à volta como na Inglaterra medieval) ou como uma superfície muito vasta e que não é vista como envolvente (como nas novas colónias americanas).

Ora também aqui, neste verbo, o estado de coisas permite realidades que podem ser encaradas como [Contentor] ou simplesmente [Lugar]. Basta reparar na tabela das aceções sem [+interioridade] de meter atrás apresentada ${ }^{8}$ para se comprovar os variadíssimos casos em que tanto é possível interpretar o mesmo lugar como contentor ou simplesmente como uma superfície sem esta particularidade.

Assim, por exemplo em "meter a cafeteira ao lume" (aceção 3) podemos imaginar o lume como contentor, envolvendo a cafeteira ou o lume não envolvendo a cafeteira, mas estando apenas a bater no fundo dela sem a circundar; em "meter energia no trabalho; meter calor na discussão" (aceção 10) pode-se conceber o trabalho/ discussão como uma "coisa" plana ou envolvente (ou talvez nem equacionar esta vertente); em "meter aquecimento central” (aceção 17) pode-se configurar o lugarsuperfície de cada elemento do aquecimento (normalmente as paredes e por isso sem serem vistas como contentores) ou então o interior da casa. Ou ainda quando a indeterminação é total, como na aceção 5 em que não se especifica que tipo de

8 Tabela Dicionário da Academia: aceções sem [+interioridade] de meter. 
lugar: "o avião mete-nos em qualquer lado; ele mete-se aí num instante". Pode-se perspetivar o destino como um espaço englobante onde nos metemos no seu interior ou um espaço de chegada, "plano", sem implicar contentor.

O processo agora descrito implica, portanto, que há estados de coisas do verbo em que a vertente [Contentor] possibilita uma dualidade de concetualizações, o que obviamente potencializa e permite a variação, como a Figura 9 procura esquematizar.

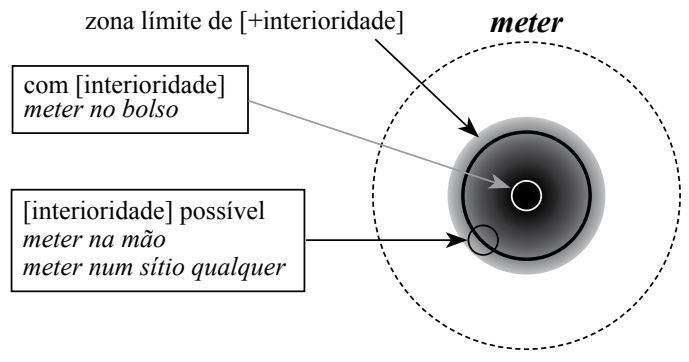

Figura 9

Como consequência deste funcionamento, perante a mesma expressão linguística (como "meter na mão") dois falantes podem construir dois modelos mentais correspondentes a duas perceções ligeiramente diferentes:

- F1 (Falante 1): a mão é entendida em concha ou potencialmente a fechar, portanto implica [+interioridade] e [Contentor];

- F2 (Falante 2): a mão é entendida como superfície, portanto não implica [+interioridade] nem [Contentor].

Assim, a estrutura do verbo para F1 será $\mathrm{X}_{\text {Agente }} M E T E R \mathrm{Y}_{\text {Objeto }}$ em $\mathrm{Z}_{\text {Contentor }}$ (meter ${ }^{l}$ ) enquanto para F2 será $\mathrm{X}_{\text {Agente }} M E T E R \mathrm{Y}_{\text {Objeto }} \mathrm{em} \mathrm{Z}_{\text {Lugar }}\left(\right.$ meter $\left.^{2}\right)$.

Note-se que esta diferença de concetualização não traz nenhum problema para F2, já que há uma relação de inclusão de [Lugar] relativamente a [Contentor], na medida em que qualquer um deles pode ser sempre visto na sua dimensão locativa, como um lugar. Por isso é que F2 pode nem se chegar a aperceber da diferença. Já F1 nota imediatamente a divergência mal F2 use [Lugar] sem [+interioridade] em vez de [Contentor], já que todos os usos de F1 cabem em F2, mas nem todos os usos de F2 cabem em F1. 


\section{O apagamento completo de [Contentor]}

O facto de a estrutura prototípica de meter assentar na noção de [Contentor] como um dos pilares-base fazia com que usos que violassem essa estrutura fossem tidos como não aceitáveis. Isto é, o estado de coisas do verbo implica que o objeto é o conteúdo, nunca podendo ser o contentor. Por isso, frases como

\section{Ela meteu a gaveta na faca.}

Vou meter a carteira na moeda.

são canonicamente tidas pelos falantes como usos anómalos, já que os estados de coisas a que são atribuídas implicariam uma gaveta a entrar para dentro de uma faca e uma carteira a entrar para dentro de uma moeda. E olhando para os inquéritos realizados, em todos eles estes usos de meter foram considerados maus por praticamente todos os falantes (ver resultados e gráficos).

No entanto, o Dicionário da Academia regista vários usos (aceção 13) em que o verbo entra precisamente com esta estrutura: o objeto é o contentor e o lugar é que passa a ser o conteúdo (meter os sapatos, um chapéu na cabeça, uma camisola, um vestido novo). Temos, portanto, para a mesma estrutura

$$
\mathrm{X}_{\text {Agente }} \text { METER } \mathrm{Y}_{\text {Contentor }} \text { em } \mathrm{Z}_{\text {Conteúdo }}
$$

graus de aceitabilidade completamente opostos:

\begin{tabular}{l|l|l|l|l}
\hline \multicolumn{1}{|c|}{$\mathrm{X}_{\text {Agente }}$} & \multicolumn{1}{|c|}{$\mathrm{Y}_{\text {Contentor }}$} & \multicolumn{1}{|c|}{ em $\mathrm{Z}_{\text {Conteúdo }}$} & ACEITABILIDADE \\
\cline { 3 - 5 } (alguém) & a gaveta & na faca & NÃO (inquéritos) \\
\cline { 3 - 5 } & a carteira & na moeda & NÃO (inquéritos) \\
\cline { 3 - 5 } & os sapatos & (nos pés) & SIM (dicionário e inquéritos) \\
\cline { 3 - 5 } & um chapéu & na cabeça & SIM (dicionário e inquéritos) \\
\cline { 3 - 5 } & uma camisola & (no corpo) & SIM (dicionário e inquéritos) \\
\cline { 3 - 5 } & um vestido novo & (no corpo) & SIM (dicionário e inquéritos) \\
\hline
\end{tabular}

Forçoso será colocar e responder a duas questões interligadas: uma que explique como é possível o verbo aceitar certos usos (os 4 últimos) com a inversão total de [Contentor/ Conteúdo] e a outra porque é que aceitando alguns não aceitar outros (os 2 primeiros).

A primeira das questões prende-se naturalmente com a reorganização da estrutura semântica do verbo que temos vindo a analisar. Na estrutura prototípica, a vertente [Contentor] no papel de meta anula naturalmente a possibilidade de um outro contentor 
no papel de objeto, implicando que o objeto seja visto como um conteúdo (um objeto que irá ser conteúdo num contentor nunca pode ser contentor do seu contentor):

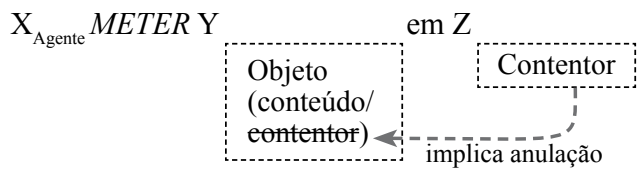

Com a alteração ocorrida, em que a meta deixa de ser obrigatoriamente [Contentor] para passar a ser apenas [Lugar], acaba essa restrição, podendo o objeto ser um contentor, já que esta perspetiva é neutralizada, não sendo considerado a sua dimensão de ser conteúdo ou ser contentor:

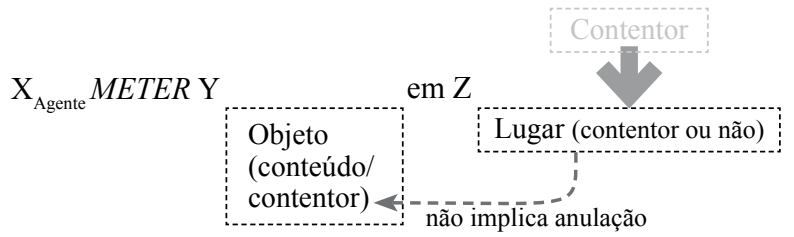

Esta estrutura irá permitir, por isso, usos como meter os sapatos (nos pés) na medida em que nem o objeto (sapatos) nem a meta (pés) são perspetivados na dimensão contentor/ conteúdo.

Mas se é assim, por que razão não são admitidos, como os resultados dos inquéritos comprovam, usos como meter a gaveta na faca ou meter a carteira na moeda?

É que embora a nova estrutura tenha anulado o funcionamento tradicional da vertente [Contentor $]^{9}$, meter implica que o seu objeto tenha sempre um traço componente exigido pelo estado de coisas do verbo: a [mobilidade]. É isto que explica que seja aceitável meter os sapatos nos pés (embora sapatos seja contentor e pés seja o conteúdo) e que em expressões deste tipo se possam trocar os argumentos do verbo sem alteração do valor atribuído ao estado de coisas (meter os sapatos nos pés $\approx$ meter os pés nos sapatos). Aqui sapatos contém o traço [+mobilidade] enquanto pés ocupa o papel de [Lugar], portanto sem o mesmo traço de [+mobilidade] (os lugares são percecionados, enquanto lugares, como realidades fixas, que não se movem). Em contrapartida, não é possível fazer o mesmo com meter a carteira na moeda porque prototipicamente

9 Embora em ROUPA/ CORPO a relação CONTEÚDO/ CONTENTOR possa ser invertida (meter roupa no corpo $=$ meter o corpo na roupa) continua a haver uma relação CONTEÚDO/ CONTENTOR, só que com papéis trocados. 
atribuímos a moeda o traço de [+mobilidade] e a carteira, nesta construção, o papel de [Lugar], portanto sem mobilidade em relação a moeda.

Note-se que podemos construir mundos possíveis que permitam interpretar meter $a$ carteira na moeda, desde que sejam atribuídos os valores referidos:

- de [+mobilidade] a carteira e de [Contentor] a moeda: uma carteira entrou dentro de uma moeda oca e enorme (maior do que a carteira);

- de [+mobilidade] a carteira e de [Lugar não Contentor] a moeda: pousou-se uma carteira em cima de uma moeda enorme.

Segue-se, de tudo o que se foi verificando, que a estrutura clássica de meter como $\mathrm{X}_{\text {Agente }}$ METER $\mathrm{Y}_{\text {Objeto }}$ em $\mathrm{Z}_{\text {Contentor }}\left(\right.$ meter $^{l}$ ) é transformada meter ${ }^{2}$ em $\mathrm{X}_{\text {Agente }}$ METER $\mathrm{Y}_{\text {Objeto movivel }}$ em $\mathrm{Z}_{\text {Lugar }}$ desaparecendo por completo o equacionamento (para aceitação ou rejeição) da vertente [Contentor] quer relativamente ao [Objeto], quer relativamente ao [Lugar].

E se em certos usos de meter, impossíveis na estrutura clássica (meter ${ }^{l}$ ), ainda podemos ser tentados a ver alguma inversão da relação contentor/ conteúdo (meter os sapatos, um chapéu na cabeça, uma camisola, um vestido novo registados pelo Dicionário da Academia) outros usos do género (como meter óculos escuros, no mesmo dicionário) evidenciam que não é a relação contentor / não contentor que está em causa. Nestes usos em que o objeto $\mathrm{Y}$ da estrutura $\mathrm{X}_{\text {Agente }} M E T E R \mathrm{Y}_{\text {Objeto }}$ movivel $\mathrm{em}_{\text {Lugar }}$ é subespecificado como [objeto de usar no corpo] (sendo portanto o lugar $\mathrm{Z}$ equivalente a [corpo humano]) nestes casos, meter fica como um termo genérico que inclui vestir (meter um casaco), calçar (meter uns sapatos novos), e ainda um outro estado de coisas para o qual não temos um termo em português (correspondente ao conceito do inglês "to wear") mas que poderá ser representado por pôr acessórios (meter uns óculos, uns brincos, uma pulseira, um relógio, etc.).

\section{Razões cognitivas e razões estruturais potenciadoras da variação}

Depois de se constatar a efetividade e a dimensão da variação existente em meter, procurou-se explicar como a estrutura actancial/argumental do verbo possibilita (ou facilita) a variação entre a presença ou ausência da vertente [Contentor] nos estados de coisas do verbo.

Olhou-se, porém, para o verbo num enfoque de isolamento em relação ao campo lexical em que o mesmo verbo se integra. No entanto, a história das mudanças linguísticas é suficientemente elucidativa para nos mostrar como os fenómenos linguísticos da variação e mudança raramente podem ser encarados isoladamente, 
constituindo-se maioritariamente como fenómenos interdependentes em que as alterações de uns acarretam alterações de outros.

No caso do verbo aqui em análise, ele é parte do grupo central dos verbos de movimento, tipicamente verbos que descrevem um estado de coisas em que um $\operatorname{Ag}($ ente) executa a ação de MOVER um O(bjeto) relativamente a um determinado L(ugar) que pode ser a Origem ou a Meta do movimento.

Classicamente, meter forma com tirar a micro estrutura primeira quando o traço de [+interioridade] de Lugar implica que este se perspetive como um [Contentor]:

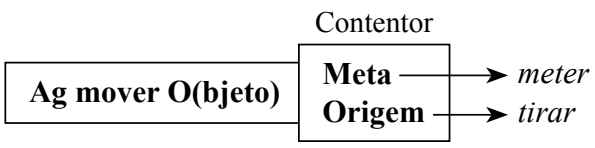

Os dois complementam-se num subgrupo que se baseia numa relação de simetria de movimento do Objeto relativamente a um Lugar [Contentor], Lugar esse que funciona como Meta para meter e como Origem para tirar:

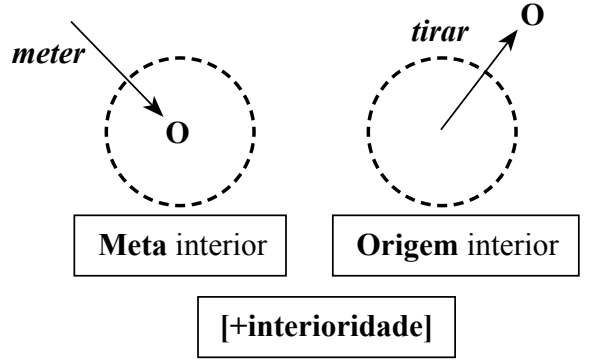

Quando a Meta não se situa obrigatoriamente num [Contentor], o estado de coisas correspondente a meter é traduzido por um outro verbo com a mesma estrutura valencial, exceto, claro, a relativa a [+interioridade] de Lugar: o verbo pôr (pôr em cima, dentro, fora, na parede...):

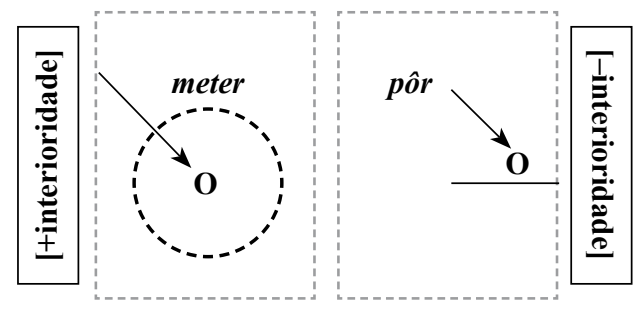


Só que este equilíbrio meter-pôr não existe para o outro par da primeiramente referida estrutura básica (o verbo tirar). Este não possui um outro tão simétrico que indique a não necessidade de [+interioridade] do objeto (como o faz o verbo pôr) e por isso o verbo tirar já perdeu há tempos a obrigatoriedade desse traço, sendo aceite em estados de coisas em que a Origem do movimento do Objeto não implica Contentor:

- tirar os pés de cima da mesa;

- tirar o risco da parede

Foi uma forma de equilibrar o sistema que tinha um lugar vazio : um estado de coisas com um Agente movimentando um Objeto de uma Origem que não era espaço considerado Contentor (sendo um Lugar sem [+interioridade]).

\begin{tabular}{l|c|c}
\multicolumn{3}{c}{ Agente MOVER Objeto } \\
& Meta & Origem \\
\hline Contentor & meter & tirar \\
\hline Não Contentor & pôr & tirar \\
\hline
\end{tabular}

Neste último esquema e no apresentado a seguir é fácil visualizar a necessidade de preenchimento de lugar vazio que o novo uso de tirar colmatou:

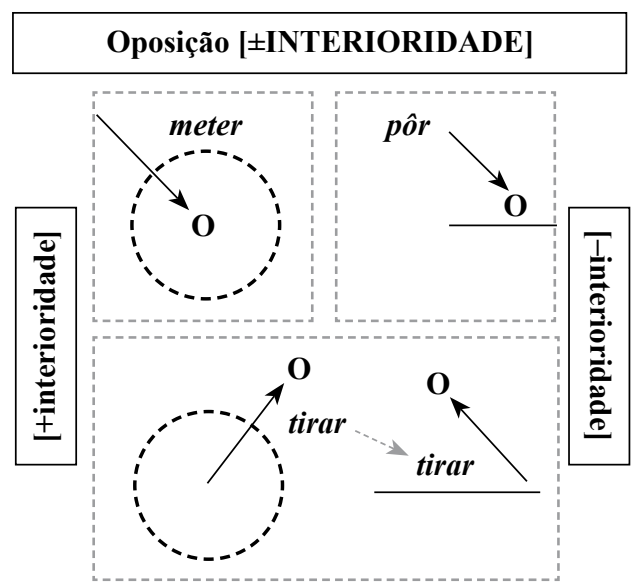


Só que na língua cada novo equilíbrio pode constituir-se fator de novo desequilíbrio.

E é o que, em nossa opinião, acontece neste quadro e explica a fortíssima tendência para a variação de meter que se vai solidificando no PE atual. Se desaparece a pertinência do vetor de [+interioridade] em tirar há uma forte motivação para desaparecer também na outra micro-estrutura meter-pôr. E assim tal como aconteceu a tirar, o valor clássico de meter (meter ${ }^{l}$ ) está agora a perder a obrigatoriedade de contentor com a nova variante ( meter $^{2}$ ) como meter os pratos na mesa, meter a música mais alto ou meter amarelo no desenho comprovam. E como o esquema evidencia há um novo equilíbrio a tentar estabelecer-se:

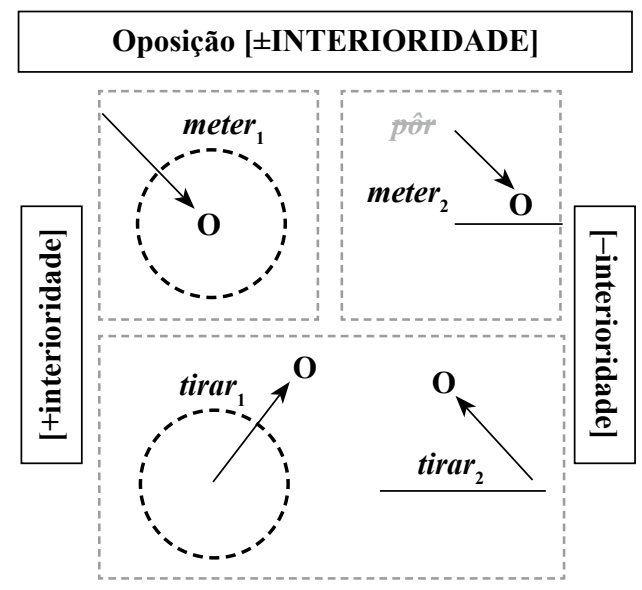

\section{Conclusões}

Pelas respostas obtidas nos inquéritos apresentados, é evidente a confirmação de como a estrutura clássica de meter vai sendo reorganizada numa nova que não inclui a obrigatoriedade de Contentor. Mas para além desta evidência factual, o mais interessante talvez seja a possibilidade de compreender melhor os (des)equilíbrios e (re)arranjos que vão acontecendo entre este verbo e outros verbos de movimento, bem assim o que a partir destas movimentações podemos inferir sobre a organização das categorias lexicais.

Assim, parece-nos lícito poder concluir-se que a aceitabilidade das construções em variação é diretamente proporcional à frequência de uso, à familiaridade do 
falante com a combinação sintagmática. Ou seja, o falante pode atribuir diferentes graus de aceitabilidade a diferentes usos da mesma estrutura morfo-semântica (e sintática), variando a aceitabilidade não em função da regra mas em função da sua familiaridade/frequência com determinadas combinatórias. Assim, embora meter a música mais alto e meter mais amarelo no desenho sejam resultantes da mesma regra, o primeiro uso parece mais aceitável porque utilizado mais frequentemente.

Outro dado que chama a atenção e que se pode deduzir a partir dos resultados é o de que o processo de reorganização de um protótipo implica não apenas uma temporalização para a reorganização, mas também que não há o abandono abrupto da organização prototípica clássica. Os falantes, mesmo utilizando a forma nova, meter $^{2}$, continuam a considerar como mais prototípico meter ${ }^{1}$. Parece, assim, haver uma certa consciência e valorização da diacronia através do reconhecimento dos usos clássicos (da geração dos mais velhos) como usos de grande aceitabilidade. E será esta uma das causas de na língua não haver substituições bruscas, mas verdadeiras alternativas entre variantes. Ora este processo prova que os inovadores usos entram através das gerações mais novas e talvez que o aumento da interação linguística com os mais velhos (com o protótipo "clássico") é um elemento retardador da transformação da variação em mudança efetivada.

Dado interessante que este processo de variação permite verificar é o de que os valores prototípicos, embora sendo valores nucleares de uma estrutura semântica, podem ser obliterados e neutralizados pelos falantes. E ainda que os esquemas espaciais implicando [Contentor], mesmo que inseridos num núcleo prototípico, facilmente podem passar a uma estrutura superordenada (digamos assim) que o inclua, como [Lugar].

Finalmente, observou-se como o desequilíbrio entre as micro-estruturas semânticas (meter-tirar; meter-pôr; tirar- $\varnothing$ ) pode ser fator potenciador da variação e como esta tende a responder às necessidades que as línguas naturais têm de fornecerem grelhas semântico-concetuais que da forma mais eficiente e mais económica possam representar as interações que temos com o mundo que percecionamos.

Certamente que é apenas um momento transitório na língua esta variação que aqui tentamos que servisse para espreitar para dentro da organização concetual. Pode dizer-se que os factos que os dados apresentados comprovam são factos passageiros. Mas por muito escorregadios e transitórios que sejam os usos concretos das línguas naturais, estes ainda são a principal luz que temos para tentar perceber como funciona a linguagem na caixa mágica da cognição humana. 


\section{Referências bibliográficas}

Rosch, E. (1973): "On the internal structure of perceptual and semantic categories", en Moore, T. (ed.), Cognitive Development and the Acquisition of Language, 111-144 (New York: Academic Press).

Rosch, E. (1975): “Cognitive representations of semantic categories”, Cognitive Psycology 7, 573-605.

Sanromán, Á. I. (2001): A Unidade Lexicográfica - Palavras, Colocações, Frasemas, Pragmatemas, Coleção Poliedro (Braga: Universidade do Minho/Centro de Estudos Humanísticos).

Silva, Augusto S. (2004): "Protótipos, imagens e metáforas, ou o experiencialismo da linguagem e do pensamento", en Dinis, A. / Curado, J. M. (orgs.), Consciência e Cognição (Braga: Publicações da Faculdade de Filosofia da U. C. P.).

Teixeira, J. (2001): A verbalização do Espaço: modelos mentais de frente/trás (Braga: Centro de Estudos Humanísticos, Universidade do Minho).

Teixeira, J. (2005): “Organização concetual das categorias e a lexicalização de um protótipo (fruta)", Diacritica Série Ciências da Linguagem 19/1, 239-280 (Braga: Universidade do Minho). Disponível em http://hdl.handle.net/1822/4509.

\section{Anexos}

\begin{tabular}{|c|c|c|c|c|}
\hline \multicolumn{5}{|c|}{ Total em Portugal (Braga e Porto) 10-21 anos } \\
\hline Frases & Bem & Esquis & Mal & TOTAIS \\
\hline 1 - Ela meteu a faca na gaveta. & 980 & 179 & 47 & 1206 \\
\hline 2 - Ela meteu a gaveta na faca. & 24 & 93 & 1078 & 1195 \\
\hline 3 - Ela mete muito amarelo no desenho. & 295 & 714 & 176 & 1185 \\
\hline 4-Mete os pratos na mesa. & 767 & 349 & 91 & 1207 \\
\hline 5-Ela meteu os sapatos nos pés. & 261 & 607 & 329 & 1197 \\
\hline 6 - Por causa do frio, vou meter um casaco mais grosso. & 441 & 502 & 252 & 1195 \\
\hline 7 - Vou meter a carteira na moeda. & 26 & 104 & 1064 & 1194 \\
\hline 8 - Mete a música mais alto! & 837 & 292 & 64 & 1193 \\
\hline 9-Para ler, preciso de meter os óculos. & 593 & 476 & 127 & 1196 \\
\hline 10 - Ele meteu as mãos em cima da cabeça! & 736 & 373 & 80 & 1189 \\
\hline
\end{tabular}




\begin{tabular}{c|r|r|r|r|r|r} 
& \multicolumn{3}{|c|}{$10-15$ anos } & \multicolumn{3}{|c}{ 15-21 anos } \\
Frases & \multicolumn{1}{|c|}{ Bem } & \multicolumn{1}{|c|}{ Esquis } & Mal & Bem & Esquis & \multicolumn{1}{c}{ Mal } \\
\hline 1 & 645 & 101 & 32 & 335 & 78 & 15 \\
\hline 2 & 12 & 57 & 699 & 12 & 36 & 379 \\
\hline 3 & 207 & 455 & 106 & 88 & 259 & 70 \\
\hline 4 & 520 & 215 & 45 & 247 & 134 & 46 \\
\hline 5 & 176 & 388 & 206 & 85 & 219 & 123 \\
\hline 6 & 317 & 318 & 133 & 124 & 184 & 119 \\
\hline 7 & 12 & 62 & 693 & 14 & 42 & 371 \\
\hline 8 & 555 & 175 & 37 & 282 & 117 & 27 \\
\hline 9 & 379 & 300 & 90 & 214 & 176 & 37 \\
\hline 10 & 480 & 234 & 48 & 256 & 139 & 32 \\
\hline
\end{tabular}

\section{Resultados parciais ${ }^{10}$ 10-15 anos em Portugal (Braga e Porto)}

\begin{tabular}{|c|c|c|c|c|c|c|c|c|c|c|c|c|c|c|c|c|c|c|c|c|c|c|c|c|c|c|c|}
\hline \multirow[b]{2}{*}{ Frases } & \multicolumn{3}{|c|}{ IMMCP } & \multicolumn{3}{|c|}{ LRMA } & \multicolumn{3}{|c|}{ SK } & \multicolumn{3}{|c|}{ MCSP } & \multicolumn{3}{|c|}{ AMGR } & \multicolumn{3}{|c|}{ EMAG } & \multicolumn{3}{|c|}{ PCGF } & \multicolumn{3}{|c|}{ EMRCS } & \multicolumn{3}{|c|}{ IS } \\
\hline & B & E & $\mathrm{M}$ & B & $\mathrm{E}$ & M & B & $\mathrm{E}$ & $\mathrm{M}$ & B & $\mathrm{E}$ & $\mathrm{M}$ & B & $\mathrm{E}$ & $\mathrm{M}$ & B & $\mathrm{E}$ & M & B & $\mathrm{E}$ & $\mathrm{M}$ & B & E & $\mathrm{M}$ & B & E & M \\
\hline 1 & 76 & 15 & 14 & 128 & 33 & 4 & 24 & 2 & 1 & 124 & 14 & 3 & 58 & 4 & 3 & 32 & 1 & 0 & 78 & 15 & 4 & 102 & 15 & 3 & 23 & 2 & 0 \\
\hline 2 & 0 & 4 & 91 & 1 & 9 & 155 & 1 & 5 & 21 & 5 & 5 & 131 & 1 & 4 & 60 & 0 & 3 & 30 & 0 & 9 & 88 & 3 & \begin{tabular}{l|l}
13 & 1
\end{tabular} & 104 & 1 & 5 & 9 \\
\hline 3 & 7 & 66 & 22 & 35 & 105 & 25 & 19 & 7 & 1 & 46 & 78 & 17 & 20 & 37 & 8 & 11 & 16 & 6 & 21 & 62 & 14 & 31 & 771 & 12 & 17 & 7 & 1 \\
\hline 4 & 55 & 35 & 5 & 112 & 47 & 6 & 24 & 5 & 0 & 100 & 29 & 12 & 51 & 13 & 1 & 21 & 8 & 4 & 69 & 27 & 11 & 66 & 48 & 6 & 22 & 3 & 0 \\
\hline 5 & 17 & 50 & 28 & 41 & 84 & 40 & 11 & 9 & 7 & 22 & 72 & 47 & 11 & 34 & 20 & 7 & 15 & 11 & 23 & 55 & 21 & 35 & 602 & 25 & 9 & 9 & 7 \\
\hline 6 & 24 & 56 & 14 & 67 & 75 & 23 & 16 & 8 & 3 & 69 & 41 & 32 & 20 & 30 & 15 & 15 & 10 & 8 & 37 & 39 & 21 & 55 & 51 & 14 & 14 & 8 & 3 \\
\hline 7 & 1 & 5 & 89 & 2 & 10 & 153 & 0 & 11 & 16 & 4 & 7 & 129 & 0 & 3 & 62 & 0 & 0 & 33 & 3 & 7 & 87 & 2 & \begin{tabular}{l|l}
9 & 1
\end{tabular} & 109 & 0 & 10 & 15 \\
\hline 8 & 66 & 26 & 2 & 125 & 37 & 3 & 20 & 4 & 2 & 109 & 23 & 10 & 50 & 12 & 3 & 24 & 5 & 4 & 61 & 28 & 8 & 81 & 36 & 3 & 19 & 4 & 2 \\
\hline 9 & 33 & 52 & 10 & 69 & 74 & 22 & 21 & 3 & 3 & 82 & 44 & 16 & 37 & 21 & 7 & 17 & 10 & 6 & 37 & 51 & 9 & 64 & 42 & 14 & 19 & 3 & 3 \\
\hline 10 & 60 & 33 & 2 & 106 & 44 & 10 & 21 & 5 & 1 & 83 & 42 & 16 & 43 & 21 & 0 & 23 & 5 & 5 & 59 & 32 & 6 & 65 & 47 & 8 & 20 & 5 & 0 \\
\hline
\end{tabular}

10 As siglas constantes em cada inquérito indicam as pessoas que fizeram a respetiva recolha de resultados: EMRCS $=$ Ermelinda Silva; $\mathrm{PCGF}=$ Paula Freitas; $\mathrm{MCSP}=$ Maria do Céu Pereira; LRMA= Liliana Alves; $\mathrm{JF}=$ Maria Júlia Ferreira; IMMCP= Isabel Maria Pereira; SK=Sofia Kiseleva; AMGR= Alice Ribeiro; EMAG= Eugénia Gomes; IS= Iuliia Serebriakova; IMTM= Isabel Madureira; LAMR= Laura Rodrigues. 


\begin{tabular}{l|r|r|r}
\multicolumn{2}{c|}{ Suíça: resultados totais 14-20 anos } \\
Frases & Bem & Esquis & Mal \\
\hline 1-Ela meteu a faca na gaveta. & 66 & 3 & 0 \\
\hline 2-Ela meteu a gaveta na faca. & 1 & 7 & 63 \\
\hline 3-Ela mete muito amarelo no desenho. & 24 & 44 & 3 \\
\hline 4- Mete os pratos na mesa. & 49 & 18 & 3 \\
\hline 5-Ela meteu os sapatos nos pés. & 17 & 35 & 19 \\
\hline 6- Por causa do frio, vou meter um casaco mais grosso. & 40 & 23 & 8 \\
\hline 7- Vou meter a carteira na moeda. & 4 & 5 & 62 \\
\hline 8- Mete a música mais alto! & 42 & 20 & 9 \\
\hline 9- Para ler, preciso de meter os óculos. & 44 & 22 & 5 \\
\hline 10-Ele meteu as mãos em cima da cabeça! & 50 & 17 & 4 \\
\hline
\end{tabular}

Resultados parciais 15-21 anos em Portugal (Braga e Porto)

\begin{tabular}{c|c|c|c|c|c|c|c|c|c|c|c|c|c|c|c|c|c|c} 
& \multicolumn{2}{|c|}{ LRMA } & \multicolumn{3}{|c|}{ IMTM } & \multicolumn{3}{|c|}{ LAMR } & \multicolumn{3}{|c|}{ AMGR } & \multicolumn{3}{|c|}{ PCGF } & \multicolumn{3}{|c}{ EMAG } \\
\hline Frases & B & E & M & B & E & M & B & E & M & B & E & M & B & E & M & B & E & M \\
\hline 1 & 69 & 21 & 4 & 49 & 11 & 0 & 56 & 10 & 5 & 75 & 5 & 1 & 31 & 23 & 1 & 55 & 8 & 4 \\
\hline 2 & 5 & 10 & 79 & 2 & 2 & 56 & 1 & 4 & 66 & 2 & 7 & 71 & 0 & 7 & 48 & 2 & 6 & 59 \\
\hline 3 & 10 & 58 & 16 & 15 & 40 & 5 & 17 & 41 & 13 & 19 & 49 & 12 & 1 & 36 & 18 & 26 & 35 & 6 \\
\hline 4 & 53 & 24 & 17 & 31 & 23 & 6 & 47 & 17 & 7 & 54 & 22 & 4 & 15 & 33 & 7 & 47 & 15 & 5 \\
\hline 5 & 19 & 43 & 32 & 13 & 22 & 25 & 15 & 35 & 21 & 12 & 48 & 20 & 6 & 37 & 12 & 20 & 34 & 13 \\
\hline 6 & 15 & 53 & 26 & 21 & 23 & 16 & 26 & 24 & 21 & 21 & 34 & 25 & 3 & 28 & 24 & 38 & 22 & 7 \\
\hline 7 & 6 & 13 & 75 & 4 & 2 & 54 & 2 & 7 & 62 & 1 & 4 & 75 & 0 & 5 & 50 & 1 & 11 & 55 \\
\hline 8 & 57 & 28 & 9 & 44 & 11 & 5 & 49 & 18 & 4 & 61 & 17 & 1 & 26 & 24 & 5 & 45 & 19 & 3 \\
\hline 9 & 45 & 43 & 6 & 38 & 15 & 7 & 35 & 30 & 6 & 45 & 28 & 7 & 16 & 30 & 9 & 35 & 30 & 2 \\
\hline 10 & 58 & 27 & 9 & 35 & 19 & 6 & 43 & 19 & 9 & 57 & 19 & 4 & 19 & 34 & 2 & 44 & 21 & 2 \\
\hline
\end{tabular}

Revista Galega de Filoloxía, ISSN 1576-2661, 2012, 13: 121-150

Data de recepción: 9 de febreiro de 2012 | Data de aceptación: 2 de abril de 2012 